\title{
Simulation of pool boiling of nanofluids by using Eulerian multiphase model
}

\author{
Mohammed Saad Kamel ${ }^{1,2}$ (D) Mohamed Sobhi Al-agha ${ }^{1} \cdot$ Ferenc Lezsovits $^{1} \cdot$ Omid Mahian $^{3,4}$
}

Received: 1 June 2019 / Accepted: 8 December 2019 / Published online: 21 December 2019

(c) The Author(s) 2019

\begin{abstract}
In the present work, a new simulation of nanofluid/vapor two-phase flow inside the 2-D rectangular boiling chamber was numerically investigated. The Eulerian-Eulerian approach used to predict the boiling curve and the interaction between two phases. The surface modification during pool boiling of silica nanofluid represented by surface roughness and wettability is put into the account in this simulation. New closure correlations regarding the nucleation sites density and bubble departure diameter during boiling of silica nanofluid were inserted to extend the boiling model in this work. Besides, the bubble waiting time coefficient which involved in quenching heat flux under heat flux partitioning HFP model was corrected to improve the results of this study. The numerical results validated with experimental works in the literature, and they revealed good agreements for both pure water and nanofluids. The results found that when improving the heat flux partitioning model HFP by considering the surface modification of nucleate pool boiling parameters, it will give more mechanistic sights compared to the classical model, which is used for predicting of boiling heat transfer of pure liquid.
\end{abstract}

Keywords Nucleate boiling $\cdot$ HFP model $\cdot$ Wettability $\cdot$ Pool boiling $\cdot$ Nanofluids

\begin{tabular}{|c|c|c|c|c|}
\hline \multicolumn{3}{|c|}{ Abbreviation } & $P(\mathrm{kPa})$ & Pressure syste \\
\hline \multicolumn{2}{|c|}{ UDFs } & User defined functions & $D_{\text {bw }}(\mathrm{mm})$ & Bubble depa \\
\hline \multicolumn{2}{|c|}{ RPI } & Rensselaer polytechnic institute & $d_{\mathrm{p}}(\mathrm{nm})$ & Particle size \\
\hline \multicolumn{2}{|c|}{ HFP } & Heat flux partitioning & $N\left(\right.$ sites $\left.\mathrm{cm}^{-2}\right)$ & Nucleation \\
\hline \multicolumn{2}{|c|}{ FVM } & Finite volume method & $R_{\mathrm{a}}(\mathrm{nm})$ & The surface \\
\hline \multicolumn{2}{|c|}{$\mathrm{CHF}$} & Critical heat flux & $T_{\mathrm{w}}(\mathrm{K})$ & Wall tempe \\
\hline \multicolumn{2}{|c|}{ PBHTC } & Pool boiling heat transfer coefficient & $C_{\mathrm{w}}(-)$ & Bubble wai \\
\hline \multicolumn{3}{|c|}{ List of symbols } & $T_{\text {sat }}(\mathrm{K})$ & Saturation \\
\hline & Total heat flux density & $\rho_{1}\left(\mathrm{~kg} \mathrm{~m}^{-3}\right)$ & The density \\
\hline \multirow{2}{*}{\multicolumn{2}{|c|}{$\begin{array}{l}q_{\text {quen }}\left(\mathrm{kW} \mathrm{m}^{-2}\right) \\
q_{\text {evap }}\left(\mathrm{kW} \mathrm{m}^{-2}\right)\end{array}$}} & Quenching heat flux & $K_{1}\left(\mathrm{~W} \mathrm{~m}^{-1} \mathrm{~K}^{-1}\right)$ & Th \\
\hline & & Evaporative heat flux & Greek letters & \\
\hline \multicolumn{3}{|c|}{$q_{\text {conv }}\left(\mathrm{kW} \mathrm{m}^{-2}\right)$} & $\varphi(\%)$ & Volume fr \\
\hline \multicolumn{3}{|c|}{$\begin{array}{l}\triangle \quad \text { Mohammed Saad Kamel } \\
\text { kamel@energia.bme.hu; kamel86@stu.edu.iq }\end{array}$} & $\beta(-)$ & Wettability \\
\hline & \multicolumn{2}{|c|}{$\begin{array}{l}\text { Department of Energy Engineering, Faculty of Mechanical } \\
\text { Engineering, Budapest University of Technology } \\
\text { and Economics, Muegyetem rkp. 3, Budapest 1111, Hungary }\end{array}$} & $\begin{array}{l}\text { Subscripts } \\
\text { atm } \\
\text { sat }\end{array}$ & $\begin{array}{l}\text { Atmospheric } \\
\text { Saturation }\end{array}$ \\
\hline 2 & \multicolumn{2}{|c|}{$\begin{array}{l}\text { Department of Mechanical Techniques, Al-Nasiriya } \\
\text { Technical Institute, Southern Technical University, } \\
\text { Thi-Qar, Al-Nasiriya 64001, Iraq }\end{array}$} & $\begin{array}{l}\mathrm{g} \\
1 \\
\text { eff }\end{array}$ & $\begin{array}{l}\text { Gases } \\
\text { Liquid } \\
\text { Effective }\end{array}$ \\
\hline 3 & \multicolumn{2}{|c|}{$\begin{array}{l}\text { School of Chemical Engineering and Technology, Xi' an } \\
\text { Jiaotong University, Xi'an, China }\end{array}$} & $\begin{array}{l}\text { w } \\
\text { sup }\end{array}$ & $\begin{array}{l}\text { Wall } \\
\text { Superheat }\end{array}$ \\
\hline & Department of & Iechanical Engineering, Quchan University & quen & Quenching \\
\hline
\end{tabular}


evap Evaporative

conv Convection

\section{Introduction}

During the last decades, considerable efforts have been made by experts of thermofluids and heat transfer to investigate the boiling heat transfer process. The high heat transfer rate that could be removed during this heat transfer mode was a massive motivation for the researchers of the heat transfer area to understand well this physical phenomenon. Boiling and twophase flow encountered in various industrial applications such as boilers tubes, evaporators, air conditioning, cooling of high heat flux dissipation electronic systems, cooling of nuclear reactors, some chemical process [1-6]. Pool boiling is a type of boiling that involves boiling of the stationary liquid inside the vessel (boiling chamber), and it is encountered in the aforementioned industrial application. To enhance the heat transfer rate during this process, many efforts have been focused on previous studies to modify the characteristics of the heating surface and use a mixture of different pure fluids [7-11], while others investigated the effect of additives to the working fluid $[12,13]$. The concept of new-engineered thermal fluids with efficient thermal properties by adding solid nanoscale material firstly introduced by Choi [14] and thus termed as "nanofluids" which are engineering colloidal suspension of nanoparticles with basefluids with the aim to intensifying the thermal conductivity of those fluids.

Pool boiling using pure liquids and nanofluids has been investigated extensively during the last decade, but knowledge on the modeling of pool boiling of nanofluids is still limited. It is widely known that the boiling of pure liquids complex and the presence of ultrafine particles increase this degree of complexity due to the interaction between exist phases, their interfaces and the heating surface [15]. Some new investigations show that many factors were affecting the pool boiling of nanofluids such as particle size, concentration, heating surface structure and bubbles dynamic; hence, studying such mechanisms theoretically need further investigations to build an accurate predictive model [16-18]. One of the most critical sub-phenomena involved in pool boiling of nanofluids is bubble dynamics during the nucleate regime; therefore, studying the bubble parameters with the presence of those ultrafine particles could result in an accurate predictive model for such mechanism. Salari et al. [19] experimentally investigated the pool boiling performance of gamma $\mathrm{Fe}_{3} \mathrm{O}_{4}$ aqueous nanofluids on a flat disk heater. They studied the influence of various operating parameters such as heat flux, nanoparticle concentration and fouling resistance on pool boiling heat transfer coefficient. Their results demonstrated that the pool boiling heat transfer coefficient increased with increasing the mass concentration and the applied heat flux.

Aminfar et al. [20] numerically studied the nucleate pool boiling of $\mathrm{SiO}_{2}$ and $\mathrm{Al}_{2} \mathrm{O}_{3}$ nanoparticle-based nanofluids on a heating surface plate. They used in their simulation two and three phases mixture models to mimic pool boiling using nanofluids; their results proved that the two-phase model was able to predict this mechanism more accurately than three-phase model using effective thermophysical properties for nanofluids. Kim et al. [21] adopted a numerical simulation of saturated water and $\mathrm{Al}_{2} \mathrm{O}_{3}$-water nanofluid on a vertical surface using the volume of the fluid model (VOF). They used different superheated temperatures with a range of $(5-20 \mathrm{~K})$ and various concentrations for nanoparticles. Their results found that there was an agreement for the size and shapes of vapor bubbles between the numerical results and the experimental measurements for all superheat temperatures. Moreover, the void fraction and the temporal heat flux increased with increasing superheat temperatures, and this is due to the enhancement of thermal conductivity with the higher volume fraction of nanoparticles.

Gobinath et al. [22] studied the thermodiffusion (soreteffect) of water-alumina nanofluid at sub-cooled pool boiling conditions numerically. They conducted an experimental investigation of pool boiling on a horizontal tube with various subcooled temperatures for alumina nanofluid to validate their model. Numerical results found to have an excellent match between the measured and prediction temperature values. The thermophoresis velocity became less effect for particle motion close to the heater surface with amplified heater inputs. Moreover, heat diffusion from particles found to be much faster than usual compared to the heat transfer due to particle Brownian motion. Ham and Cho [23] investigated the effect of volume fraction and nanoparticles size on $\mathrm{Al}_{2} \mathrm{O}_{3}$ nanofluid numerically using the heat flux partitioning model (HFP). They used different contact angles for liquid-surface interaction to examine the critical heat flux $\mathrm{CHF}$ for water and nanofluid. Different concentrations of nanoparticles, as well as particle size, used to see their effect on CHF and bubble dynamics. They concluded from their investigation that the nanofluid has a higher $\mathrm{CHF}$ about $1509 \mathrm{~kW} / \mathrm{m}^{2}$ than water as a working for surface roughness about $0.1 \mu \mathrm{m}$ and concentration $0.025 \mathrm{vol} \%$, and this value becomes higher than other volume fraction and similar for other size particles. Moreover, the frequency of bubble departure reduced, and the bubble departure diameter increased at higher nanofluid volume fraction, but these bubble dynamics parameters not influenced by nanoparticle size under the same operating conditions. Mahdavi et al. [24] studied the pool boiling of nanofluid behavior numerically on two horizontal tubes with the various inclination and pitch distance by adopting the Eulerian-Lagrangian approach. They implemented new closure correlations in their model as a user-defined function 
for nucleation sites density and bubble departure diameter based on the nanoparticle deposition effect and surface roughness enhancement for nanofluids. On another hand, they model the particle effect by tracking them everywhere in the physical domain via the lagrangian approach by using the discrete phase model (DFM). Their results detected that the percentage of deposition is dependent on heat flux and particle volume fraction. Besides, heat transfer performance increases with increasing the pitch distance of the tubes. Moreover, the numerical results show good agreement to those of experimental study in the literature. Numerical study of nucleate pool boiling using ferrofluids by applying non-uniform magnetic field on horizontal surface is adopted by Mohammadpourfard et al. [25]. They predicted heat and mass transfer during pool boiling phenomena under affecting the negative and positive gradient of the magnetic field via a mixture model. Results of the simulation study found an agreement to experimental data, and the heat transfer performance increased by applying the negative gradient magnetic field for ferro-particles compared to those of the absence of a magnetic field. Moreover, the existence of a magnetic field with a negative gradient led to elongate the bubbles in the direction of the magnetic line. Mortezazadeh et al. [26] used the eulerian-eulerian framework to predict the nucleate pool boiling of ferrofluid with a magnetic field. They also modified the heat flux-partitioning model under the boiling model to including the boiling parameters in their account. Their results showed that using nanoparticles causes degradation in the boiling heat transfer performance and void fraction. Moreover, using the magnetic field enhanced those reductions.

Up to date and according to the reported literature, there is still no robust model or correlation to predict nucleate pool boiling of nanofluids precisely. Efforts are going on to conduct more experimental investigations to get extensive empirical or semi-empirical correlations regard to heat and mass transfer during pool boiling of nanofluids and their sub phenomena such as bubbles dynamic, surface interaction and transient conduction to build a robust model. Hence, in this simulation, efforts have been made to predict the nucleate pool boiling heat transfer mechanism using a boiling model under a two-phase Eulerian approach, which included and implemented new closure correlations related to boiling parameters such as bubble departure diameter, nucleation site density from experimental work in the literature. Moreover, the bubble waiting time coefficient in the quenching heat flux part was corrected via try and error procedure and correlated to superheat temperature for the first time to predict pool boiling heat transfer using silica-based water nanofluid with dilute volume concentration.
Assumptions and theoretical formulation

\section{Assumption}

In the Eulerian multiphase scheme (two-fluid model), the liquid behaves as the continuous phase, and vapor bubbles are the disperse phase. Due to near molecular mixing between the dilute concentration of nanoparticles and the base fluid, a nanofluid hydro dynamically behaves as it is pure base fluid, and therefore, single-phase modeling of nanofluid is reasonable to assume. On another hand, it was also believed that the vapor-phase is not dense enough to hold the nanoparticles within so, we assumed that the thermal properties of the vapor phase were not influenced by stable nanoparticles, as suggested by [16-18, 26].

\section{Governing equations}

Two sets of conservation equations governing the balance of mass, momentum, and energy of each phase are presented as follows $[15,27]$ :

\section{Continuity equation}

$\frac{\partial\left(\rho_{\mathrm{k}} \alpha_{\mathrm{k}}\right)}{\partial t}+\nabla \cdot\left(\rho_{\mathrm{k}} \alpha_{\mathrm{k}} v_{\mathrm{k}}\right)=\dot{\mathrm{m}}_{\mathrm{kj}}$

\section{Momentum equation}

$$
\begin{aligned}
& \frac{\partial\left(\rho_{\mathrm{k}} \alpha_{\mathrm{k}} v_{\mathrm{k}}\right)}{\partial t}+\nabla \cdot\left(\rho_{\mathrm{k}} \alpha_{\mathrm{k}} v_{\mathrm{k}} v_{\mathrm{k}}\right) \\
& =\alpha_{\mathrm{k}} \nabla P-\rho_{\mathrm{k}} \alpha_{\mathrm{k}} g+\nabla\left[\alpha_{\mathrm{k}} \mu_{\mathrm{k}}^{e}\left(\nabla v_{\mathrm{k}}+\left(\nabla v_{\mathrm{k}}\right)^{T}\right)\right] \\
& \quad+\left(\dot{\mathrm{m}}_{\mathrm{kj}} v_{\mathrm{k}}+\dot{\mathrm{m}}_{\mathrm{jk}} v_{\mathrm{j}}\right)+S_{\mathrm{kj}}
\end{aligned}
$$

\section{Energy equation}

$$
\begin{aligned}
& \frac{\partial\left(\rho_{\mathrm{k}} \alpha_{\mathrm{k}} E_{\mathrm{k}}\right)}{\partial t}+\nabla \cdot\left(\rho_{\mathrm{k}} \alpha_{\mathrm{k}} v_{\mathrm{k}} E_{\mathrm{k}}\right) \\
& \quad=\nabla\left[\alpha_{\mathrm{k}} k_{\mathrm{k}}^{e}\left(\nabla T_{\mathrm{k}}\right)\right]+\left(\dot{\mathrm{m}}_{\mathrm{kj}} E_{\mathrm{k}}+\dot{\mathrm{m}}_{\mathrm{jk}} E_{\mathrm{j}}\right)+S_{\mathrm{kj}}
\end{aligned}
$$

where; the subscripts of $k$ and $j$ are phase denotations ( $k$, $\mathrm{j}=\mathrm{l}$ for the liquid phase and $\mathrm{k}, \mathrm{j}=\mathrm{g}$ for vapor phase.

In these equations $\dot{\mathrm{m}}_{\mathrm{kj}}$ is interfacial mass transfer in the liquid phase on the surface heater. In the bulk liquid, this quantity is equal to zero. This is because pool boiling begins at a saturation temperature. $\left(\dot{\mathrm{m}}_{\mathrm{kj}} v_{\mathrm{k}}+\dot{\mathrm{m}}_{\mathrm{jk}} v_{\mathrm{j}}\right)$, in the momentum, the equation represents the momentum transfer due 
to liquid evaporation or vapor condensation. In addition, $\left(\dot{\mathrm{m}}_{\mathrm{kj}} E_{\mathrm{k}}+\dot{\mathrm{m}}_{\mathrm{jk}} E_{\mathrm{j}}\right)$ in the energy, equation stands for the energy transfer due to phase change.

\section{Phase interaction mechanism}

In the present simulation, to solve the governing equations formulating the phase interaction that related to interfacial momentum, heat and mass transfer are included. Firstly, for the viscous model, there are two typical flow regimes, which are the laminar and the turbulent models; due to the physical nature of vapor bubbles and the dynamics related to them, it was considered a chaotic phenomenon, and then the rough model with two equations $k-\varepsilon$ model is selected as it is recommended by [15]. The interaction between the liquid-vapor phases could induce some forces such as drag force, lift force, wall lubrication force, and turbulent dispersion force. In the present simulation, we focused on the following models in order to mimic the phase interaction. Ishii [28] model was adopted in this simulation as follows:

$C_{\mathrm{D}}=\operatorname{Min}\left(C_{\mathrm{D}, \mathrm{vis}}, C_{\mathrm{D}, \mathrm{dis}}\right)$

where; $C_{\mathrm{D}}$, is the drag coefficient and is determined by selecting the minimum of $C_{\mathrm{D} \text {, vis }}, C_{\mathrm{D} \text {,dis }}$ which are the viscous regime and the distorted regime coefficients, respectively. The formula of those coefficients given by the following expressions:

$C_{\mathrm{D}, \text { vis }}=\frac{24}{\mathrm{Re}}\left(1+0.15 \mathrm{Re}^{0.75}\right)$

$C_{\text {D,dis }}=\frac{2}{3} \frac{d_{\text {bubble }}}{\sqrt{\frac{\sigma}{G\left(\rho_{1}-\rho_{\mathrm{g}}\right)}}}$

where; Re is the relative Reynolds number as shown in Eqs. (7), (8), $\sigma$ is the surface tension, and $G$ is the gravitational acceleration and $d_{\text {bubble }}$ is the bubble diameter (note: all units for physical quantities shown in nomenclatures list). The relative Reynolds number for the water phase (1) and vapor phase $(\mathrm{g})$ defined as:

$\operatorname{Re}=\frac{\rho_{1}\left|\vec{V}_{\mathrm{g}}-\vec{V}_{1}\right| d_{\mathrm{g}}}{\mu_{1}}$

In this work, the effects of turbulent dispersion forces that account for the interphase turbulent momentum transfer were included. The chaotic dispersion force acts as a turbulent diffusion in dispersed flows. The Lopez de Bertodano [29] model for turbulent dispersion force of bubbles dispersion was utilized in this simulation as follow:
$\vec{F}_{\mathrm{td}, \mathrm{l}}=-\vec{F}_{\mathrm{td}, \mathrm{g}}=C_{\mathrm{TD}} \rho_{\mathrm{l}} K_{\mathrm{l}} \nabla \varphi_{\mathrm{g}}$

where; $\rho_{1}$ is the continuous phase density (water or nanofluid), $K_{1}$ is the turbulent kinetic energy for continuous phase, $\nabla \varphi_{\mathrm{g}}$ is the gradient of dispersed phase volume fraction (vapor), finally, $C_{\mathrm{TD}}$ is a user-modifiable constant and this by default equal to 1 .

For heat transfer between the continuous phase (water) and the dispersed phase (vapor) was included, and this transferred energy could accrue due to the non-thermal equilibrium across the interphase [12]. To determine the heat transfer coefficient between the continuous and dispersed phases $\left(h_{\mathrm{gl}}=k_{\mathrm{l}} N u_{\mathrm{g}} / d_{\text {bubble }}\right)$, the Ranz-Marshall model $[30,31]$ was selected in this work to model the heat transfer via phase interaction; the following expression represented this model.

$N u_{\mathrm{g}}=2.0+0.6 \operatorname{Pr}_{1}^{0.333} \operatorname{Re}_{\mathrm{g}}^{0.5}$

where; $\operatorname{Re}_{\mathrm{g}}$ is the relative Reynolds number based on the diameter of the dispersed phase (bubble diameter), and relative velocity $\left|\overrightarrow{V_{\mathrm{g}}}-\overrightarrow{V_{1}}\right|$, and $\operatorname{Pr}_{1}$ is the Prandtl number of the continuous phase (water) as follows.

$\operatorname{Pr}=\frac{C_{\mathrm{p}, 1} \mu_{1}}{k_{1}}$

where; $C_{\mathrm{p}, 1}, \mu_{1}$, and $k_{1}$ are the specific heat, viscosity and thermal conductivity of continuous phase (water), respectively.

\section{Heat flux-partitioning model (HFP)}

The heat and mass transfer during the nucleate pool boiling of pure liquids has been commonly predicted by using the Rensselaer Polytechnic Institute model [32, 33], which is called the RPI model. In this classic boiling model, the total heat flux $\dot{q}_{\text {total }}$ from the surface is governed by three heat transfer mechanisms: the heat flux due to the natural convection that represented by the energy transfer from the formation bubbles to the bulk liquid $\dot{q}_{\text {conv }}$, the heat flux due to the latent heat of vaporization $\dot{q}_{\text {evap }}$, and the heat flux due to quenching $\dot{q}_{\text {quen }}$, which is the process of the periodic averaged transient energy transfer related to liquid filling the wall vicinity after bubble separation [15-18].

$\dot{q}_{\text {total }}=\dot{q}_{\text {conv }}+\dot{q}_{\text {evap }}+\dot{q}_{\text {quen }}$

where, $\dot{q}_{\text {conv }}, \dot{q}_{\text {evap }}$ and $\dot{q}_{\text {quen }}$ represent the total heat flux components transferred by natural convection, evaporation, and quenching, respectively.

$\dot{q}_{\text {conv }}=\left(1-A_{\text {quen }}\right) \times h_{\text {conv }} \times\left(T_{\mathrm{w}}-T_{1}\right)$ 
$\dot{q}_{\text {evap }}=\frac{\pi}{6} D_{\mathrm{bd}}^{3} \rho_{\mathrm{v}} f N_{\mathrm{a}} h_{\mathrm{fg}}$

$\dot{q}_{\text {quen }}=\frac{2}{\sqrt{\pi}} f A_{\text {quen }} \sqrt{t_{\mathrm{w}} \lambda_{1} \rho_{1} C_{\mathrm{p}, 1}}\left(T_{\mathrm{w}}-T_{1}\right)$

where, $D_{\mathrm{bd}}, f, N_{\mathrm{a}}, A_{\text {conv }}, A_{\text {quen }}$ and $t_{\mathrm{w}}$ are the bubble departure diameter, bubble frequency, active nucleation sites, the area fractions of the heater surface related to convection and quenching mechanisms, and the bubble waiting time, respectively.

According to our best knowledge, nucleate pool boing parameters, especially the nucleation of bubbles and their departure diameters could be affected by the porous layer, which high on the heating surface during the boiling of nanofluids. Therefore, efforts should be put to take into account the modification of the heating surface due to the deposition of nanoparticles through a pool boiling phenomenon. There are vast correlations in the literature that described the pool boiling parameters of pure liquids and those correlations successful in validating the boiling of conventional fluids. To predict the nucleate boiling using nanofluids, the settings above must be formulated according to the modification of the heating surface characteristics.

A semi-analytic model was introduced by [34] to predict the active site density. In this model, the effect of nanoparticle deposition on bubble nucleation sites was introduced. The wettability enhancement parameter and nanoparticle size relative to the surface roughness were included, as shown in Eq. (15). effects of particle size relative to the surface roughness could be adequately considered, Eq. (17) was reformulated in this work by the following expression:

$$
\begin{aligned}
N= & \frac{512}{\gamma} \operatorname{Pr}_{1}^{1.63}\left[14.5-4.5\left(\frac{P R_{\mathrm{a}}}{\sigma}\right)+0.4\left(\frac{P R_{\mathrm{a}}}{\sigma}\right)^{2}\right] \\
& \beta^{-0.4} \xi\left(\frac{R_{\mathrm{a}}}{d_{\mathrm{p}}}\right)^{0.4} \Delta T_{\text {sup }}^{3}
\end{aligned}
$$

where:

$$
\xi\left(\frac{R_{\mathrm{a}}}{d_{\mathrm{p}}}\right)=\left\{\begin{array}{l}
0.275\left(\frac{R_{\mathrm{a}}}{d_{\mathrm{p}}}\right)^{-1.2}\left(\frac{R_{\mathrm{a}}}{d_{\mathrm{p}}}\right) \leq 1.0 \\
0.275+0.7911\left(\frac{R_{\mathrm{a}}}{d_{\mathrm{p}}}-1\right)^{0.68}\left(\frac{R_{\mathrm{a}}}{d_{\mathrm{p}}}\right)>1.0
\end{array}\right.
$$

where $\gamma$ is the wall-liquid interaction parameter that is defined in Eq. (19), and it is re-defined in the above correlation due to the deposition of the nanoparticles layer.

$\gamma=\sqrt{\frac{\lambda_{\mathrm{p}} \rho_{\mathrm{p}} C_{\mathrm{p}, \mathrm{p}}}{\lambda_{1} \rho_{1} C_{\mathrm{p}, 1}}}$

Li et al. [18] proposed a new correlation of nucleation site density by fitting data of nanofluids experimental study, and for the purpose of validation of the present model, we inserted this correlation as UDF in this study.

$N=1.206 \times 10^{4}(1-\cos \theta) \Delta T_{\text {sup }}^{2.06}$

$N=218.8 \frac{1}{\gamma} \operatorname{Pr}_{1}^{1.63}\left\{\left[14.5-4.5\left(\frac{P R_{\mathrm{a}}}{\sigma}\right)+0.4\left(\frac{P R_{\mathrm{a}}}{\sigma}\right)^{2}\right] \beta^{-3}\left(\frac{R_{\mathrm{a}}}{d_{\mathrm{p}}}\right)^{-0.5}\right\}^{-0.4} \Delta T_{\text {sup }}$

where $P, R_{\mathrm{a}}$ and $d_{\mathrm{p}}$ stand for the pressure, average surface roughness, and nanoparticle diameter, respectively. Moreover, $\gamma$ is the wall-liquid interaction parameter determined by the surface and liquid materials, and $\beta$ is the surface wettability improvement parameter described as follow:

$\beta=\frac{1-\cos \theta}{1-\cos \theta^{*}}$

where $\theta$ and $\theta^{*}$ are the liquid contact angle on the nanocoated and clean surface, respectively.

Das et al. [35] showed that heat transfer by nanofluids was degraded when $R_{\mathrm{a}} / d_{\mathrm{p}}$ value reaches 1.0 ; otherwise, heat transfer enhanced as $R_{\mathrm{a}} / d_{\mathrm{p}}$ was away from 1.0. They proposed when $R_{\mathrm{a}} / d_{\mathrm{p}}$ was near 1.0, deposited nanoparticles reduce the active site density. Otherwise, when the surface roughness and particle size were slightly far from more active site density would be created. Therefore, so that the
On another hand, bubble departure diameter is also considered as an essential boiling parameter and needs more attention if we are looking to predict the boiling of nanofluids. Many correlations regarding bubble departure diameter are available in the literature for experimental data of pure liquid, but it is still challenging to observe that for nanofluid nucleate boiling. As aforementioned in previous sections, the modification for surface characteristics due to the nanoparticle deposition during the boiling of nanofluids has a significant effect on bubble departure. Phan et al. [36] suggested that the enhancement of wettability has affected the bubble departure, and they proposed a correlation based on the Fritz correlation in which the contact angle is included.

$d_{\mathrm{bw}}=0.626977 \frac{2+3 \cos \theta-\cos ^{3} \theta}{4} \sqrt{\frac{\sigma}{g\left(\rho_{1}-\rho_{\mathrm{g}}\right)}}$ 
This correlation is still limited, while other essential influence parameters are neglected. Up to date, it is challenging to formulate a robust correlation of the bubble departure diameter for pure liquids, not to mention so many merits in using nanofluids that makes them very challenging. In the present study and for the purpose of simplification, a polynomial correlation was utilized by fitting the data of Gerardi et al. [37], and this was used by [18], in previous work.

$$
\begin{aligned}
d_{\mathrm{bw}}= & -1.91 \times 10^{-3}+4.21125 \times 10^{-4} \Delta T_{\text {sup }} \\
& -1.70945 \times 10^{-5} \Delta T_{\text {sup }}^{2}+2.03938 \times 10^{-7} \Delta T_{\text {sup }}^{3}
\end{aligned}
$$

The bubble departure frequency was correlated to $d_{\mathrm{bw}}$ as widely observed to have a tendency to this parameter, and it was found to be decreased as bubble departure diameter increased, and this by means both pure liquids and nanofluids. It defined as:

$$
f \sim \frac{1}{d_{\mathrm{bw}}^{n}}
$$

The index $n$ has a various values in most popular correlations, for instance, the Stephan correlation [18, 38] Eq. (24) the index $=(1.5)$, and in Cole correlation Eq. (25) [18] the index $=(0.5)$, Hatton-Hall correlation $[18,39]$ is equal (2) Eq. (26).

$f=\frac{1}{\pi} \sqrt{\frac{\mathrm{g}}{2 d_{\mathrm{bw}}}\left(1+\frac{4 \sigma}{d_{\mathrm{bw}}^{2} \rho_{1} \mathrm{~g}}\right)}$

$f=C_{\mathrm{f}} \sqrt{\frac{4 \mathrm{~g}\left(\rho_{1}-\rho_{\mathrm{g}}\right)}{3 d_{\mathrm{bw}} \rho_{1}}}$

$f=284.7 \frac{\lambda_{1}}{d_{\mathrm{bw}}^{2} \rho_{1} C_{\mathrm{p}, 1}}$

Finally, we modified the quenching correction model that deals with quenching heat flux from the heating surface by fitting the bubble waiting time coefficient to superheat temperatures of Akbari et al. [40] experimental data as written in Eq. (28). This correction model predicts the cyclic averaged transient energy associated with liquid filling the heating surface vicinity after bubble detachment with a cyclic time $t$, and this can be expressed as:

$$
\begin{aligned}
& q_{\text {quen }}=C_{\mathrm{wt}} \frac{2 k_{1}}{\sqrt{\pi \alpha_{1} t}}\left(T_{\mathrm{w}}-T_{1}\right) A_{\text {quen }} \\
& C_{\mathrm{wt}}=0.1+2.5 \times\left[1-\mathrm{e}^{-\left(\frac{\Delta T_{\mathrm{sup}}}{22.422}\right)^{5.9}}\right]
\end{aligned}
$$

where, $k_{1}$ is the conductivity of the liquid, $t$ is the periodic time and $\alpha_{1}$ is the diffusivity of the liquid phase and $C_{\mathrm{wt}}$ is the bubble waiting time coefficient, and it is introduced to correct the waiting time for bubble departure and consecutive (the default value for this coefficient is equal to 1 ).

\section{Boundary conditions}

In the present work, the aforementioned governing equations are subjected to the following boundary conditions:

1. A constant temperature is assumed to be at the heating surface

$$
T=T_{\mathrm{w}}
$$

2. Heat flux is zero at the adiabatic walls

$$
q^{\prime \prime}=-K_{\mathrm{w}} \frac{\partial T}{\partial \mathrm{x}}=0
$$

3. At the top of the boiling chamber, the pressure is assumed to be atmospheric pressure

$P=P_{\text {atm }}$

\section{Physical domain and the numerical method}

In this study, the physical geometry is a rectangular chamber, and it was drawn in 2-Dimension, as illustrated in Fig. 1. The heating surface located in the center of the bottom chamber with $40 \mathrm{~mm}$, and the dimension of the pool boiling chamber were $(300 \times 150 \mathrm{~mm})$. The geometry was chosen as the experimental boiling chamber of [40] for the purpose of validation, and to ensure that it will not tolerate any edge effects on the vicinity of the heating wall to avoid the bubble capillary forces from the sides wall. As mentioned in $\mathrm{Li}$ et al. $[17,18]$ work, the time of transient initial stage was usually short and the nucleate pool boiling using nanofluids was mostly characterized by a quasi-steady state; hence, in this work the nucleate boiling was carried out at steady state

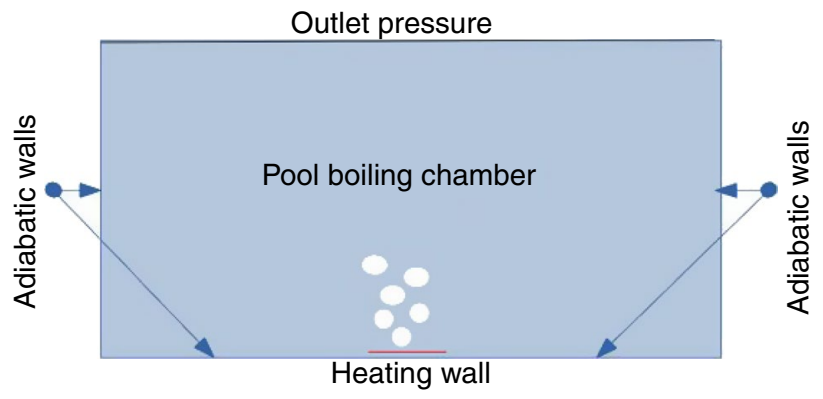

Fig. 1 Geometry description of pool boiling model 
by ignoring the time derivative in the first term on the left hand that appears in Eq. (1), and this was also highlighted by works in the literature [15, 27]. Moreover, we compared the heat flux results from the steady-state and transient solutions, and the difference was negligible at different superheat cases. The transport equations are discretized by using finite volume method FVM that is solved via commercial CFD code (Fluent solver). In order to build the computational mesh, we used the meshing tool available in ANSYS software. The physical domain in this study involved a structured uniform meshes based on a rectangular shape. All the closure correlations related to nucleate boiling of nanofluids that adopted in this work incorporated into the fluent solver as user-defined functions UDFs. The convergence criteria were achieved at 10000 iterations.

\section{Thermophysical properties of nanofluid}

In the present work, dilute volume concentration ( $0.01 \mathrm{vol} \%)$ of $\mathrm{SiO}_{2}$ nanoparticles was used to study the pool boiling heat transfer of silica nanofluid. Due to the low volume concentration used in this study, we assumed that there no bulk property modification happens with this type of nanofluids. The negligibility assumption is approved by models of thermos-physical properties with dilute volume concentration, which are used in this work. Hence, the effective properties of nanofluid do not deviate significantly from that of pure water. In addition, surface tension property for nanofluid was considered to be the same as pure water due to the dilute concentration used in this study. The thermophysical properties of pure water, vapor and nanofluids at saturation temperature $100{ }^{\circ} \mathrm{C}[41]$ are shown in Table 1 . The following mixture of thermal properties correlations of nanofluids utilized in the present work.

- Density, used by [26]

$$
\rho_{\text {eff }}=\varphi \rho_{\mathrm{p}}+(1-\varphi) \rho_{1}
$$

- Heat capacity, used by [26]

$$
C_{\mathrm{p}, \text { fff }}=\frac{\varphi \rho_{\mathrm{p}} C_{\mathrm{p}, \mathrm{p}}+(1-\varphi) \rho_{1} C_{\mathrm{p}, 1}}{\varphi \rho_{\mathrm{p}}+(1-\varphi) \rho_{1}}
$$

- Thermal conductivity, introduced by [42]

$$
K_{\text {eff }}=K_{1}\left[\frac{K_{\mathrm{p}}+2 K_{1}-2 \varphi\left(K_{1}-K_{\mathrm{p}}\right)}{K_{\mathrm{p}}+2 K_{1}+\varphi\left(K_{1}-K_{\mathrm{p}}\right)}\right]
$$

- Viscosity, introduced by [43]

$$
\mu_{\mathrm{eff}}=\frac{\mu_{1}}{(1-\varphi)^{-2.3}}
$$

\section{Results and discussion}

\section{Model validation with experimental data}

In the present numerical study, the boiling model (RPI model) with two forms: the classical RPI model (without any extending for bubble dynamics parameters, and using the default bubble waiting time coefficient $C_{\mathrm{w}}=1$ ), and that the extended boiling parameters in parallel with a corrected one $C_{\mathrm{w}}$ as shown in Eq. (28), was firstly validated with experimental data of [40] and the well-known Rohesnow correlation, as shown in Fig. 2. The boiling curve for the heat flux against superheat temperatures in the nucleate boiling

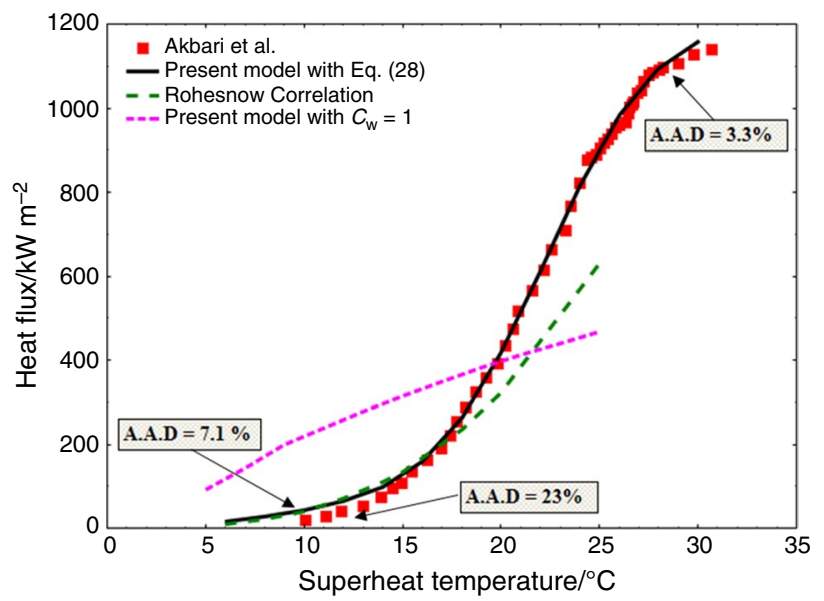

Fig. 2 The boiling curve of pure water for the present model compared to experimental data of Akbari et al. [40], and Rohesnow correlation [44]
Table 1 Thermophysical properties of working fluids used in this simulation at saturation temperature condition $\left(100{ }^{\circ} \mathrm{C}\right)$

\begin{tabular}{lclc}
\hline Property & Water [41] & Vapor [41] & $\begin{array}{c}(0.01 \% \text { vol }) \mathrm{SiO}_{2} / \text { water } \\
\text { nanofluid [26, 42, 43] }\end{array}$ \\
\hline Density $/ \mathrm{kg} \mathrm{m}^{-3}$ & 958.35 & 0.59817 & 958.47 \\
Specific heat $/ \mathrm{J} \mathrm{kg}^{-1} \mathrm{~K}^{-1}$ & 4215.7 & 2080 & 4214.9 \\
Thermal conductivity $/ \mathrm{W} \mathrm{m}^{-1} \mathrm{~K}^{-1}$ & 0.67909 & 0.02509 & 0.67909 \\
Dynamic viscosity $/ \mathrm{Pa} \mathrm{s}$ & 0.000281 & 0.0000122 & 0.000281 \\
Surface tension $/ \mathrm{N} \mathrm{m}^{-1}$ & 0.0589 & - & 0.0589 \\
\hline
\end{tabular}


regime, which revealed a reasonable agreement with pure water experimental results of [40] with an absolute average deviation A.A.D about $23 \%$ and $3.3 \%$ in low and high heat fluxes respectively. This result was probably due to the fact that the closure correlations included in the RPI model were based on data of experimental studies of pure liquids. Moreover, the geometry that is used for validation purposes for the present model was chosen according to [40]. Secondly, the current model was also validated against the classic Rohsenow correlation for pure water [44], and the results showed excellent compatibility with an A.A.D of about 7.1\% at low heat fluxes.

As aforementioned in the HFP model description in the previous section and for the first time, we corrected a new bubble waiting time coefficient $C_{\mathrm{w}}$ for quenching heat flux correction model at the RPI boiling model by fitting the experimental data of [40], as shown in Fig. 3. The results seem to be more acceptable with experimental data for heat flux against the superheat temperature, while the model with the default value of this bubble waiting time coefficient correction model was mainly over prediction to experimental data as depicted in Fig. 4. In addition, it was widely believed that the nucleation site density is a critical boiling parameter, and the boiling of nanofluids could change the surface characteristics then might increase or reduce the number of the nucleation sites. In this work, we examined this parameter to validate our model. The active nucleation sites density predicted by the present HFP model obtained from fitting the experimental data of [37] and used by [17, 18]. It was inserted as UDF in the boiling parameters list of the present model, and the results show good agreement with experimental results of the literature as depicted in Fig. 5. Moreover, it is evident that the comparison of the nucleation site density also showed that the Das et al. [35] correlation was also able to predict this parameter adequately.

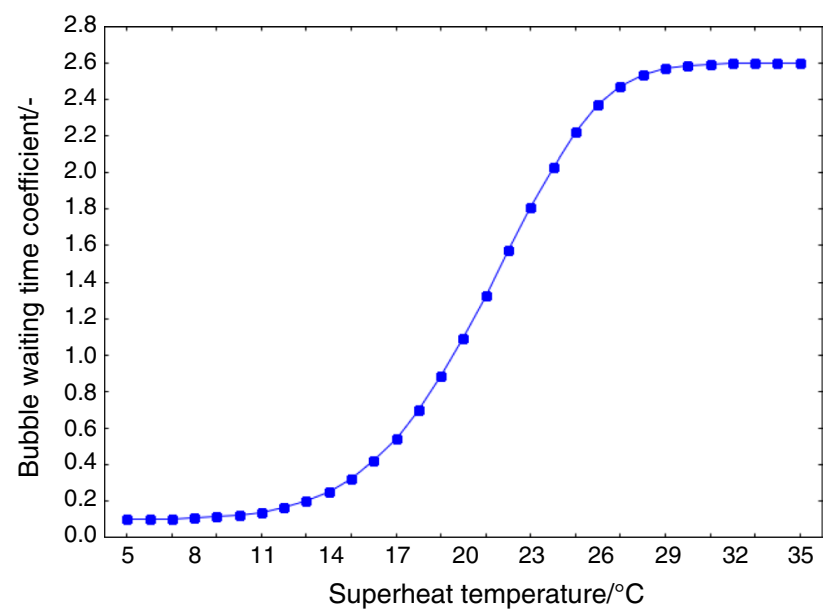

Fig. 3 A bubble waiting time coefficient against the superheat temperature of the present quenching correction model Eq. (28)

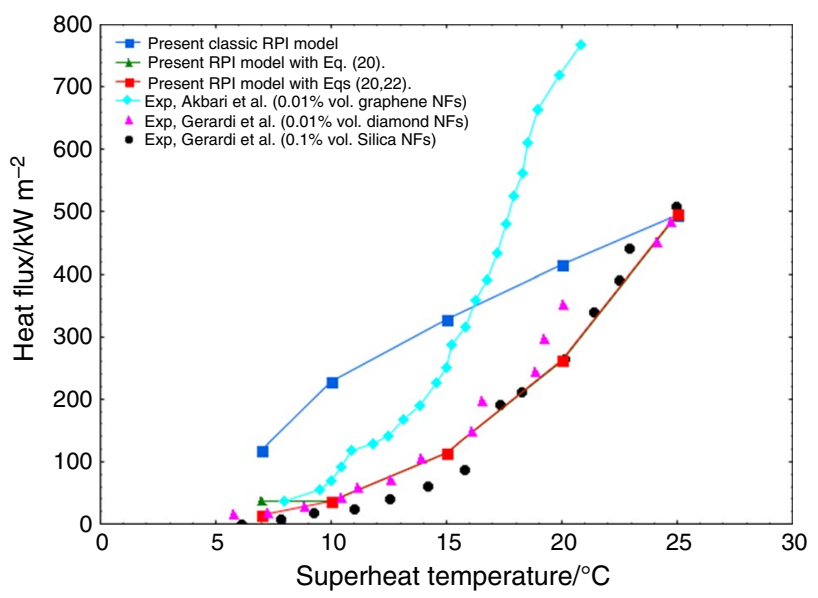

Fig. 4 Comparison of boiling curves of the present numerical results against the experimental data of Gerardi et al. [37], and Akbari et al. [40]

Bubble departure diameter was also considered as an essential boiling parameter when modeling nucleate boiling phenomenon, and as reported by previous studies that this parameter could significantly be influenced by many factors such as the superheat temperature, surface properties, pressure system as well as liquid properties [18, 37, 45]. Bubble departure diameter of nanofluids increased when the superheat going to grow at a certain level, and then, it will be decreasing as superheat temperature continues to increase, and this trend noticed by [37]. Predicting of bubble departure diameter in the present model was successfully done by comparison of the incorporated UDF by using Eq. (22) for the current extended model and the experimental data of Gerardi et al. [37], which are used for silica and graphene nanofluids under atmospheric pressure condition. Figure 6 shows the bubble departure diameter against superheat

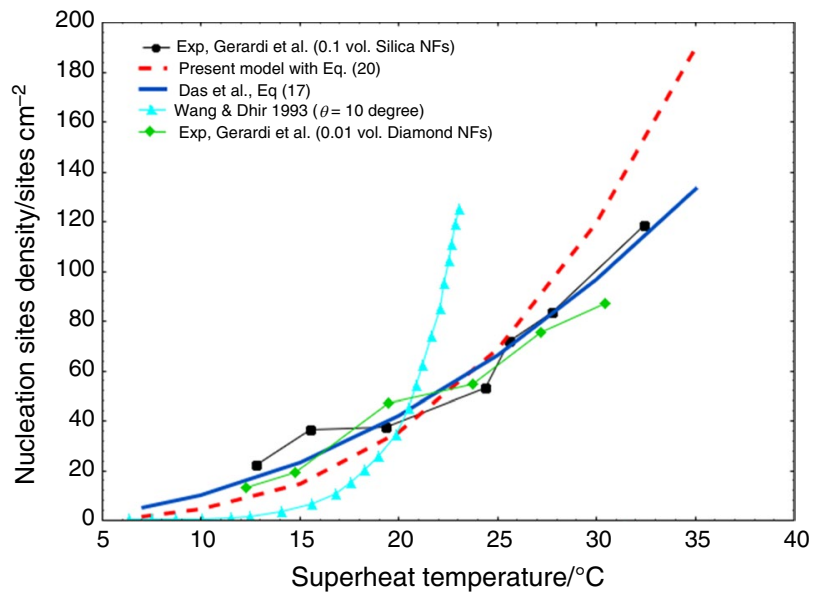

Fig. 5 Results of nucleation sties density against superheat temperature for the present model and closures correlations from the literature 


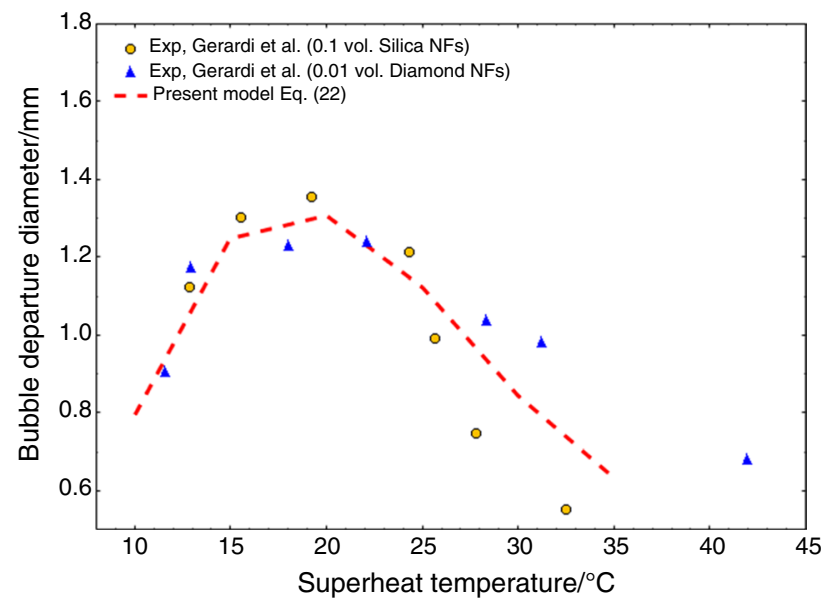

Fig. 6 Bubble-departure diameter against superheat temperature in the present model compared to the experimental data of Gerardi et al. [37]
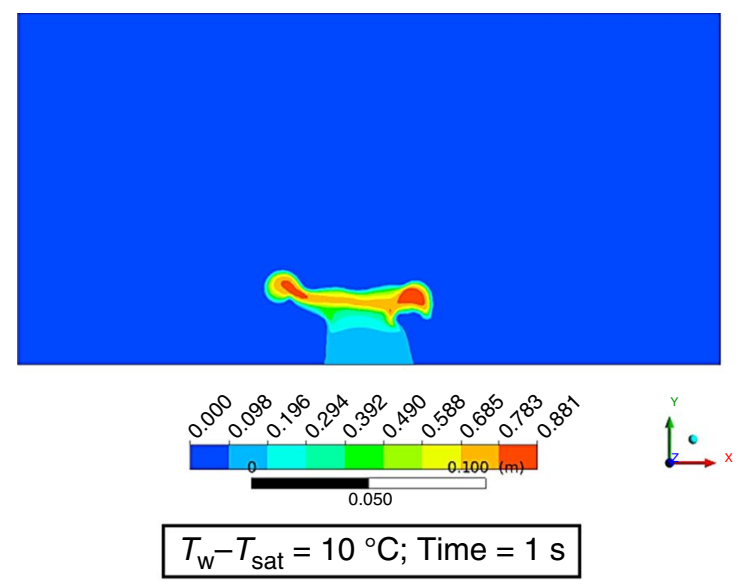

(a)

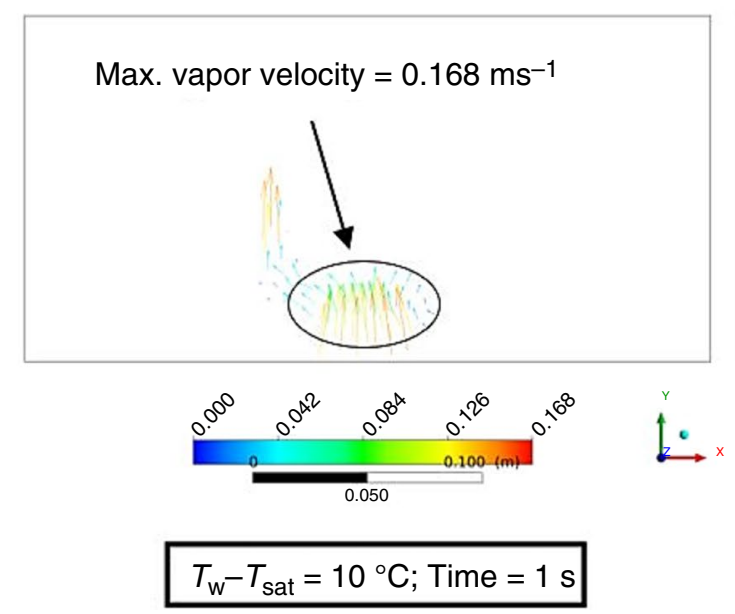

temperature for the present model compared to experimental data, and the average absolute deviation was about $11 \%$ between the current model and the experimental data in the literature. It can be concluded that the pool boiling parameters were inserted in this model could predict the surface modification well when using nanofluids. Moreover, further studies should be focus to predict the bubble departure diameter with the influence of the pressure system, and the surface and fluid properties to obtain a comprehensive correlation could be used for the boiling of nanofluids.

\section{Void fraction of present model}

Figure 7a shows the contours of the vapor volume fraction of pool boiling using silica nanofluid with different superheat temperatures at the time ( $1 \mathrm{~s}$ ) by adopted transient simulation using above-mentioned extended model. As can be seen, the volume fraction of vapor phase increased with increasing

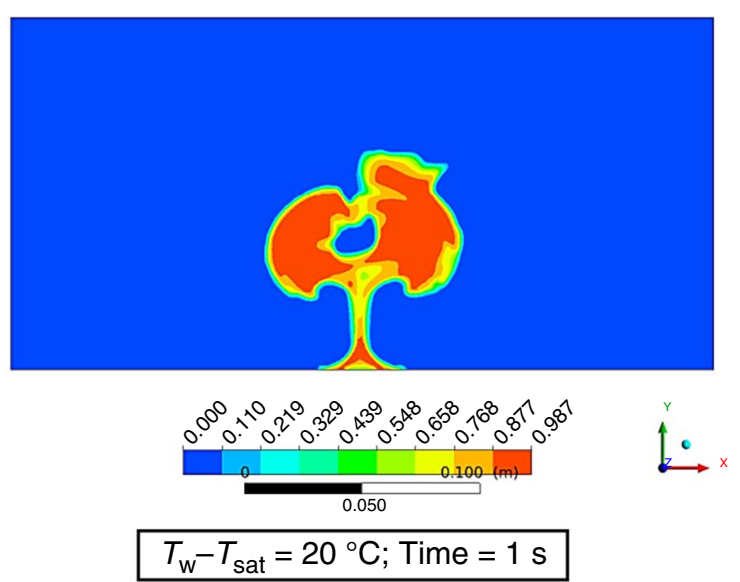

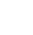

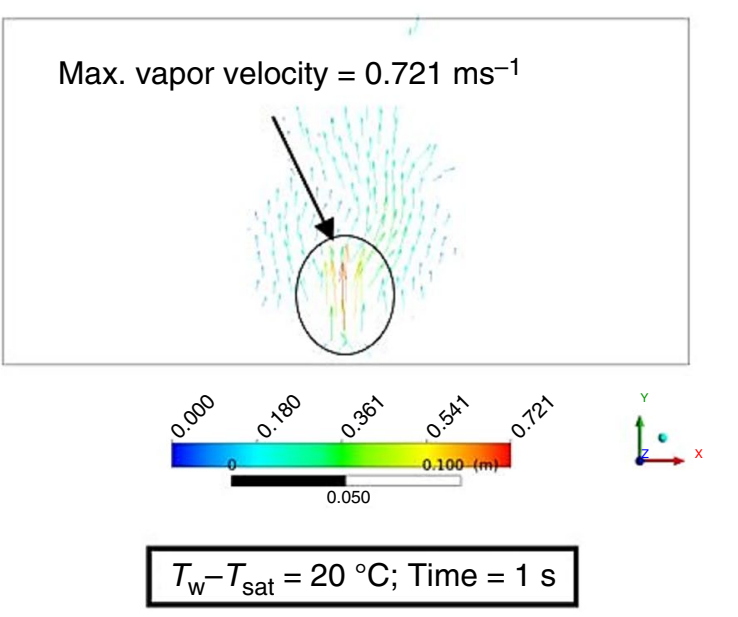

(b)

Fig. 7 a Contours of a vapor void fraction of nanofluid at different superheat temperatures, $\mathbf{b}$ vectors of a vapor velocity of nanofluid at different superheat temperatures 
the superheat temperatures, and this is due to the formation of the bubble during the nucleate boiling regime as the temperature of heating surface increase the nucleation site density of bubbles starts to improve, and more agent bubbles become dominate on the heating surface. The motion of those bubbles going up due to the buoyancy effect close to the top of the boiling chamber. However, in this study, we focused on presenting the contours of vapor volume fraction of nanofluid/vapor simulation because there is no remarkable difference in colors of void fractions depicted for both pure water and nanofluid/vapor results. Hence, in the next step, we tried to plot the void fractions with a variation of superheat temperatures in vertical distance from the center of the heating surface and by mean both water and nanofluid. Figure $7 \mathrm{~b}$ presents the vapor velocity vectors at the time (1 s), during the nanofluids/vapor phases. As can see the velocity of bubbles starts from the center of the enclosure from the heated surface, and on the corners, there is no bubbles formation to avoid the effect of side wall force on bubbles motion. The velocity of bubbles increases as superheat temperature increases, and this is due to the increasing bubbles formations from sites of the nucleation process on the heated surface. The motion of bubbles column form the center of the heated wall at superheat temperature $\left(\mathrm{T}_{\mathrm{w}}-\mathrm{T}_{\text {sat }}=20^{\circ} \mathrm{C}\right)$ accelerate when the bubble becomes like mushroom shape, which makes it significant with a velocity slower than the velocity of the upward bubbles column because of the resistance of effect bulk fluid over it. The velocity of vapor during the boiling process is considered an important issue due to the dependence of condenser functionality in the two-phase condensation process. Hence, the predicting of vapor velocity could be useful for pool boiling experiments using nanofluid.

Figure 8 illustrates the vapor void fractions along the vertical direction from the center of the heating wall to the

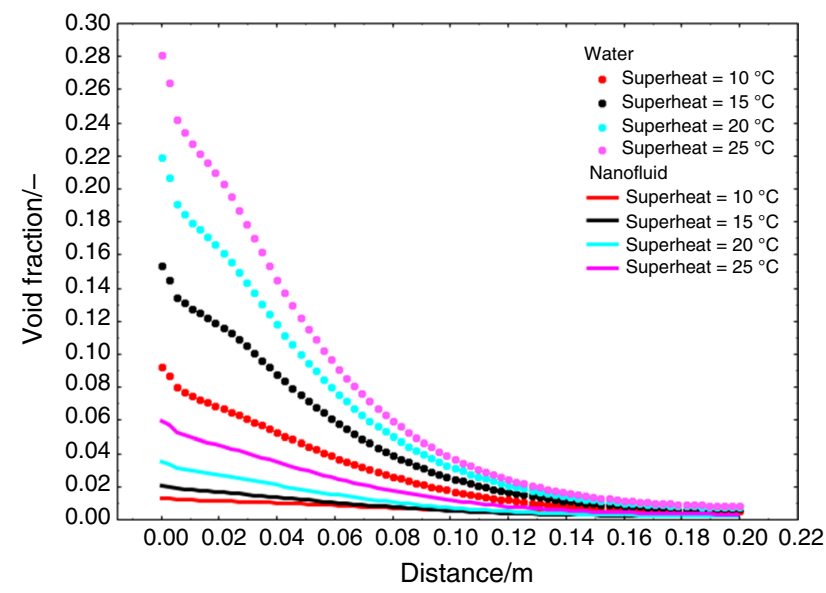

Fig. 8 The void fraction of the vapor phase for pure water and nanofluid along the vertical distance with various superheat temperatures top of the boiling chamber for both water and nanofluid. It can be seen that the volume fraction for all cases (water and nanofluids) increased with raising the superheat temperature, and this could be attributed to the formation of more bubbles with high frequencies and size. On another hand, the void fraction of nanofluid noted to be less than the void fraction of water, and this is due to the interaction of nanoparticles with vapor bubbles in bulk fluid, and this trend was studied by $[46,47]$. In addition, the void fraction near the heating surface (voided region) was more predominant than another area, and this is due to the high heat flux in this region. It can be seen that for nanofluid with small contact angle about $\left(23^{\circ}\right)$, which is used in this study as suggested by [37], the wettability was enhanced by means of the decrease in contact angle due to the surface modification during the boiling of silica nanofluid. Hence, less void fraction in this region than pure water, and this is due to the deposition of nanoparticles during the boiling process, which, in turn, modified the surface contact angle via enhancing the capillary wicking force and reducing the nucleation sites by filled the microcavities in surface structure.

\section{Heat transfer coefficient and HFP components}

In the present model, results obtained for pool boiling heat transfer coefficient against applied heat flux for water and silica nanofluids are shown in Fig. 9. It can be clearly seen from the curves that the HTC for nanofluids was degraded compared to pure water especially for high heat flux values and this trend noted by experimental data of [37], while the finding of [40] detected that the nanofluids could enhance the heat transfer coefficient and this contradictory in results may be due to the type of nanofluids and the thermophysical properties that be used in their studies as well the

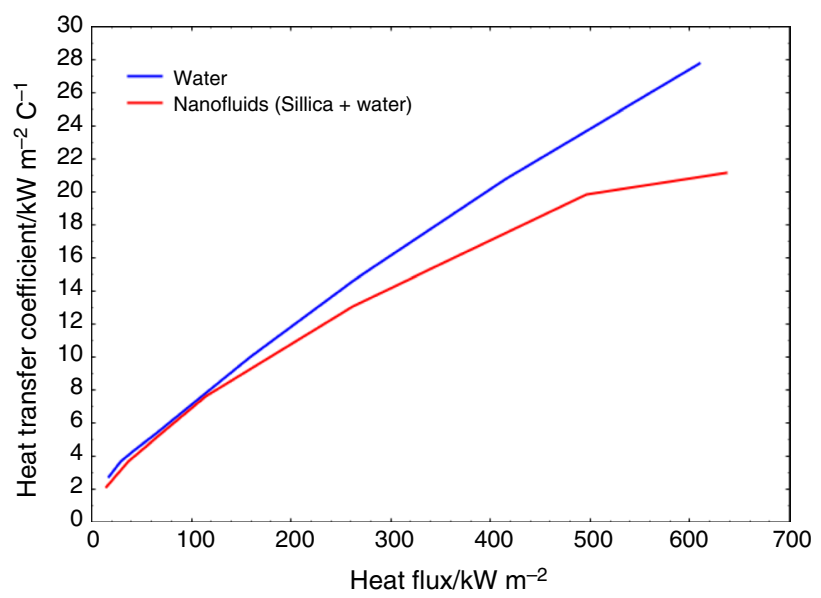

Fig. 9 Pool boiling heat transfer coefficient against heat flux for pure water and silica nanofluid predicted by the present model at volume concentration $(0.01 \%$ vol. $)$ 


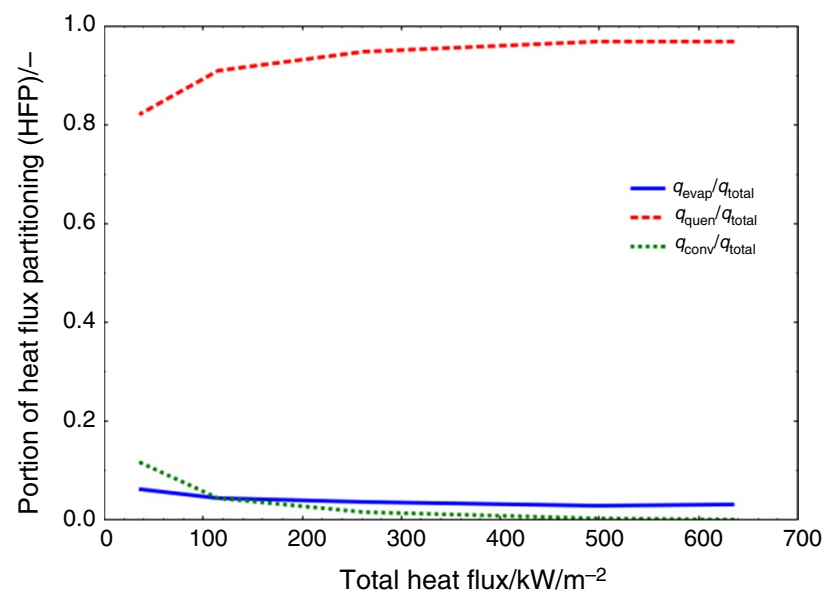

Fig. 10 The fractions of heat flux components of the present RPI model against the total heat flux

concentration of nanoparticles. The main influence mechanism that could affect the reduction of HTC for nanofluid is that the deposition of nanoparticles on the heating surface during the boiling process. The deposition of those nanoparticles build up the porous nano-layer on the heating surface, and this nano-layer mainly created due to the microlayer evaporation process, which in turn, modified the surface characteristics that could enhance wettability by reducing the contact angle between the liquid and surface. In addition, the porous nano-layer on the heating surface could be a thermal resistance layer that could hinder the rate of heat transfer from the surface to a liquid. Figure 10 depicts the components of heat flux partitioning of the present model for silica nanoparticles mixing with water after correction of quenching model for a boiling model that has been introduced in Eq. (28). The heat flux-partitioning model HFP shows that the quenching heat flux plays a significant role, among other heat flux mechanisms. It can be seen that the heat removal from heating wall more significant compared to evaporating and convection heat flux for all values of total heat flux and this could be attributed to using quenching correction model for fitting the experimental data of Gerardi et al. [37], and this correlation was as a function of superheat temperature. Besides, in the present model, we focused on the nucleate boiling regime, and this agrees well with finding that reported by some previous studies [17, 48].

\section{Conclusions}

Numerical simulation of pool boiling heat transfer for pure water and silica-based water nanofluid were carried out. The heat flux partitioning model under the boiling model was used to express the heat and mass transfer mechanisms. A new correlation for the correction of a bubble waiting time coefficient was proposed and shown good agreement with the experimental data of pool boiling of pure water. In the case of nanofluid, the numerical model was integrated with user-defined functions UDFs for boiling parameters such as bubble-departure diameter and nucleation site density to take into account the surface modification during pool boiling of nanofluid. The results demonstrated that the vapor volume fraction of pure water is more significant than that of silicabased water nanofluids for a given value of superheat temperature, and this is could be attributed to the deposition of nanoparticles on the heating surface during the boiling process. Also, the pool boiling heat transfer coefficient results demonstrated that the PBHTC of nanofluid is lower than that of pure water. Moreover, the results showed that quenching heat flux plays a major role among other heat fluxes mechanisms. Finally, to introduce a comprehensive model of pool boiling using nanofluids, more data from experimental studies should be taken in the account in the future to obtain new closure correlations related to the bubble dynamics and surface modification during boiling of nanofluids.

Acknowledgements Open access funding provided by Budapest University of Technology and Economics (BME). The authors acknowledge the Hungary Government for their financial support as the Stipendium Hungaricum Scholarship. In addition, the authors would like to thank the Tempus Public Foundation (TPF) in Hungary for their continued administrative support since the application stage until graduation.

\section{Compliance with ethical standards}

Conflict of interest The authors declare that they have no conflict of interest.

Open Access This article is licensed under a Creative Commons Attribution 4.0 International License, which permits use, sharing, adaptation, distribution and reproduction in any medium or format, as long as you give appropriate credit to the original author(s) and the source, provide a link to the Creative Commons licence, and indicate if changes were made. The images or other third party material in this article are included in the article's Creative Commons licence, unless indicated otherwise in a credit line to the material. If material is not included in the article's Creative Commons licence and your intended use is not permitted by statutory regulation or exceeds the permitted use, you will need to obtain permission directly from the copyright holder. To view a copy of this licence, visit http://creativecommons.org/licenses/by/4.0/.

\section{References}

1. Kamel MS, Lezsovits F, Hussein AK. Experimental studies of flow boiling heat transfer by using nanofluids: a critical recent review. J Therm Anal Calorim. 2019. https://doi.org/10.1007/ s10973-019-08333-2.

2. Li X, Pok Cheung SC, Tu J. Nucleate boiling of dilute nanofluids-mechanism exploring and modeling. Int J Therm Sci. 2014;84:323-34.

3. Kamel MS, Lezsovits F. Boiling heat transfer of nanofluids: a review of recent studies. Therm Sci. 2017;23(1):109-24. https:// doi.org/10.2298/TSCI170419216K. 
4. Jothi Prakash CG, Prasanth R. Enhanced boiling heat transfer by nano structured surfaces and nanofluids. Renew Sustain Energy Rev. 2018;82:4028-43.

5. Kamel MS, Lezsovits F, Hussein AM, Mahian O, Wongwises S. Latest developments in boiling critical heat flux using nanofluids: a concise review. Int Commun Heat Mass Transf. 2018;98:59-66.

6. Sarafraz MM, Peyghambarzadeh SM, Alavi Fazel SA. Experimental studies on nucleate pool boiling heat transfer to ethanol/ $\mathrm{meg} / \mathrm{deg}$ ternary mixture as a new coolant. Chem Ind Chem Eng Q. 2012;18:577-86.

7. Dong L, Quan X, Cheng P. An experimental investigation of enhanced pool boiling heat transfer from surfaces with micro/ nano-structures. Int J Heat Mass Transf. 2014;71:189-96.

8. Liang G, Mudawar I. Review of pool boiling enhancement by surface modification. Int J Heat Mass Transf. 2019;128:892-933.

9. Dehghani-ashkezari E, Salimpour MR. Effect of groove geometry on pool boiling heat transfer of water-titanium oxide nanofluid. Heat Mass Transf. 2018. https://doi.org/10.1007/s0023 1-018-2388-1.

10. Sarafraz MM, Alavi Fazel SA, Hasanzadeh Y, Arabshamsabadi A, Bahram S. Development of a new correlation for estimating pool boiling heat transfer coefficient of $\mathrm{meg} / \mathrm{deg} /$ water ternary mixture. Chem Ind Chem Eng Q. 2012;18:11-8.

11. Sarafraz MM. Experimental investigation on pool boiling heat transfer to formic acid, propanol and 2-butanol pure liquids under the atmospheric pressure. J Appl Fluid Mech. 2013;6:73-9.

12. Shoghl SN, Bahrami M. Experimental investigation on pool boiling heat transfer of $\mathrm{ZnO}$, and $\mathrm{CuO}$ water-based nanofluids and effect of surfactant on heat transfer coefficient. Int Commun Heat Mass Transf. 2013;45:122-9.

13. Dikici B, Eno E, Compere M. Pool boiling enhancement with environmentally friendly surfactant additives. J Therm Anal Calorim. 2014;116:1387-94.

14. Choi SU, Eastman JA. Enhancing thermal conductivity of fluids with nanoparticles. Lemont: Argonne National Lab; 1995.

15. Salehi H, Hormozi F. Numerical study of silica-water based nanofluid nucleate pool boiling by two-phase Eulerian scheme. Heat Mass Transf. 2018;54:773-84.

16. Li X, Li K, Tu J, Buongiorno J. On two-fluid modeling of nucleate boiling of dilute nanofluids. Int J Heat Mass Transf. 2014;69:443-50

17. Li X, Yuan Y, Tu J. A theoretical model for nucleate boiling of nanofluids considering the nanoparticle Brownian motion in liquid microlayer. Int J Heat Mass Transf. 2015;91:467-76.

18. Li X, Yuan Y, Tu J. A parametric study of the heat flux-partitioning model for nucleate boiling of nanofluids. Int $\mathbf{J}$ Therm Sci. 2015;98:42-50.

19. Salari E, Peyghambarzadeh SM, Sarafraz MM, Hormozi F, Nikkhah V. Thermal behavior of aqueous iron oxide nanofluid as a coolant on a flat disc heater under the pool boiling condition. Heat Mass Transf. 2017;53:265-75.

20. Aminfar H, Mohammadpourfard M, Sahraro M. Numerical simulation of nucleate pool boiling on the horizontal surface for nanofluid using wall heat flux partitioning method. Comput Fluids. 2012;66:29-38.

21. Kim HG, Hwang IJ, Kim SM. Numerical study on the pool boiling heat transfer of water-based nanofluids on a vertical surface. J Nanosci Nanotechnol. 2017;17:8404-10.

22. Gobinath N, Venugopal T, Palani K, Samuel AA. Numerical modeling of thermophoresis in water-alumina nanofluid under pool boiling conditions. Int J Therm Sci. 2018;129:1-13.

23. Ham J, Cho H. Theoretical analysis of pool boiling characteristics of $\mathrm{Al}_{2} \mathrm{O}_{3}$ nanofluid according to volume concentration and nanoparticle size. Appl Therm Eng. 2016;108:158-71.
24. Mahdavi M, Sharifpur M, Meyer JP. Exploration of nanofluid pool boiling and deposition on a horizontal cylinder in Eulerian and Lagrangian frames. Int J Heat Mass Transf. 2018;125:959-71.

25. Mohammadpourfard M, Aminfar H, Sahraro M. Numerical simulation of nucleate pool boiling on the horizontal surface for ferrofluid under the effect of non-uniform magnetic field. Heat Mass Transf. 2014;50:1167-76.

26. Mortezazadeh R, Aminfar H, Mohammadpourfard M. Eulerian-Eulerian simulation of non-uniform magnetic field effects on the ferrofluid nucleate pool boiling. J Eng Thermophys. 2017;26:580-97.

27. Abadi SMANR, Ahmadpour A, Meyer JP. Numerical simulation of pool boiling on smooth, vertically aligned tandem tubes. Int J Therm Sci. 2018;132:628-44.

28. Ishii M. Two-fluid model for two-phase flow. In: 2nd international workshop on two-phase flow fundamentals. Troy, NY: RPI; 1979.

29. Lopez de Bertodano M. Turbulent bubbly flow in a triangular duct. Ph.D. Thesis. Troy, New York: Rensselaer Polytechnic Institute; 1991.

30. Ranz WE, Marshall WR. Vaporation from drops, part I. Chem Eng Prog. 1952;48(3):141-6.

31. Ranz WE, Marshall WR. Evaporation from drops, part I and part II. Chem Eng Prog. 1952;48(4):173-80.

32. Kurul N, Podowski M. On the modeling of multidimensional effects in boiling channels ANS. In: Proceedings of 27th national heat transfer conference, Minneapolis, MN, USA; 1991.

33. Kurul N, Podowski M. Multidimensional effects in forced convection subcooled boiling. In: Proceedings of the ninth international heat transfer conference, vol. 2, Jerusalem, Israel; 1990. pp. 21-26.

34. Ganapathy H, Sajith V. Semi-analytical model for pool boiling of nanofluids. Int J Heat Mass Transf. 2013;57:32-47.

35. Das SK, Narayan GP, Baby AK. Survey on nucleate pool boiling of nanofluids: the effect of particle size relative to roughness. J Nanopart Res. 2008;10:1099-108.

36. Phan HT, Caney N, Marty P, Colasson S, Gavillet J. Surface wettability control by nanocoating: the effects on pool boiling heat transfer and nucleation mechanism. Int J Heat Mass Transf. 2009;52:5459-71.

37. Gerardi C, Buongiorno J, Hu LW, Mckrell T. Infrared thermometry study of nanofluid pool boiling phenomena. Nanoscale Res Lett. 2011;6:1-17.

38. Stephan K. Heat transfer in condensation and boiling. New York: Springer; 1992.

39. Hatton AP, Hall IS. Photographic study of boiling on prepared surfaces. In: The 3rd international heat transfer conference, Chicago, Illiois, USA; 1966. pp. 24-37.

40. Akbari A, Fazel SAA, Maghsoodi S, Kootenaei AS. Pool boiling heat transfer characteristics of graphene-based aqueous nanofluids. J Therm Anal Calorim. 2018. https://doi.org/10.1007/s1097 3-018-7182-2.

41. Lemmon EW, McLinden MO, Friend DG. Thermophysical properties of fluid systems in NIST chemistry WebBook, NIST Standard Reference Database Number 69. https://doi.org/10.18434/ T4D303. Retrieved 3 Nov 2019.

42. Hamilton RL, Crosser OK. Thermal conductivity of heterogeneous two-component systems. Ind Eng Chem Fundam. 1962;1:187-91.

43. Brinkman HC. The viscosity of concentrated suspensions and solutions. J Chem Phys. 1952;20:571-81.

44. Rohsenow WM. A method of correlating heat transfer data for surface boiling liquids. Trans ASME. 1952;74:969-79.

45. Narayan GP, Anoop KB, Das SK. Mechanism of enhancement/ deterioration of boiling heat transfer using stable nanoparticle suspensions over vertical tubes. J Appl Phys. 2007;102:1-7. https:// doi.org/10.1063/1.2794731. 
46. Rana KB, Agrawal GD, Mathur J, Puli U. Measurement of void fraction in flow boiling of $\mathrm{ZnO}$-water nanofluids using image processing technique. Nucl Eng Des. 2014;270:217-26.

47. Liaw SP, Dhir VK. Void fraction measurements during saturated pool boiling of water on partially wetted vertical surfaces. J Heat Transf. 1989;111(3):731-8.
48. Končar B, Kljenak I, Mavko B. Modelling of local two-phase flow parameters in upward subcooled flow boiling at low pressure. Int J Heat Mass Transf. 2004;47:1499-513.

Publisher's Note Springer Nature remains neutral with regard to jurisdictional claims in published maps and institutional affiliations. 